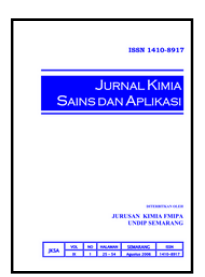

\title{
Pengaruh Temperatur terhadap Jumlah Produk Hidrorengkah Fraksi Aspalten dari Aspal Buton dengan Katalis Mo-Ni $/ \gamma^{-}$ Alumina
}

\author{
Rahmad Nuryanto ${ }^{\mathrm{a}^{*}}$, Wega Trisunaryanti ${ }^{\mathrm{b}}$, M. Utoro Yahya $^{\mathrm{b}}$ \\ a Physical Chemistry Laboratory, Chemistry Department, Faculty of Sciences and Mathematics, Diponegoro University, Jalan Prof. \\ Soedarto, Tembalang, Semarang 50275 \\ b Physical Chemistry Laboratory, Chemistry Department, Faculty of Mathematics and Natural Sciences, Gadjah Mada University \\ * Corresponding author: nuryantorahmad@live.undip.ac.id
}

\begin{tabular}{|c|c|}
\hline Article Info & Abstract \\
\hline \multirow[t]{2}{*}{ 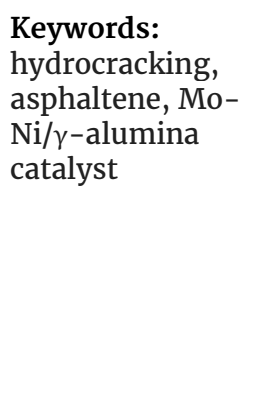 } & $\begin{array}{l}\text { Hydrocracking process of Butonian asphalt derived asphaltene using } \mathrm{Mo}-\mathrm{Ni} / \gamma \text {-alumina } \\
\text { catalyst has been investigated. The processes were carried out in } 1 \mathrm{~L} \text { stainless steel } \\
\text { autoclave reactor. The reaction temperatures were } 250,300,350 \text { and } 400^{\circ} \mathrm{C} \text {, initial } \\
\text { pressure was } 10 \mathrm{~atm} \text { and catalyst/feed ratio was } 1 / 2 . \text { The asphaltene was a Pentane } \\
\text { insoluble-benzene soluble (PI-BS) fraction of Butonian asphalt. The results of } \\
\text { hydrocracking processes showed the conversion by means of } 100 \%-\text { coke (wt } \% \text { ) was } \\
\text { followed conversion equation } \%(\mathrm{w} / \mathrm{w})=0.306 \mathrm{t}\left({ }^{\circ} \mathrm{C}\right)-41.29\end{array}$ \\
\hline & Abstrak \\
\hline $\begin{array}{l}\text { Kata kunci: } \\
\text { Hidrorengkah, } \\
\text { aspal, katalis Mo- } \\
\text { Ni } / \gamma \text {-alumina }\end{array}$ & $\begin{array}{l}\text { Telah dilakukan kajian tentan proses hidrorengkah aspal Buton yang berasal dari aspal } \\
\text { menggunakan katalis } \mathrm{Mo}-\mathrm{Ni} / \gamma \text {-alumina. Prosesnya dilakukan dalam reaktor autoclave } \\
\text { stainless steel } 1 \mathrm{~L} \text {. Suhu reaksi adalah } 250,300,350 \text { dan } 400^{\circ} \mathrm{C} \text {, tekanan awal adalah } 10 \\
\text { atm dan rasio katalis/umpan adalah } 1 / 2 \text {. Asphaltene adalah fraksi terlarut pentana tak } \\
\text { larut-benzena (PI-BS) dari aspal Buton. Hasil proses hidrorengkah menunjukkan } \\
\text { konversi dengan rata-rata } 100 \% \text { - kokas (wt } \% \text { ) diikuti persamaan konversi } \%(\mathrm{~b} / \mathrm{b})= \\
0,306 \mathrm{t}\left({ }^{\circ} \mathrm{C}\right)-41,29\end{array}$ \\
\hline
\end{tabular}

\section{Pendahuluan}

Aspal Buton merupakan salah satu dari kekayaan alam Indonesia. Kandungan aspal yang dimiliki pulau Buton cukup tinggi, namun belum dimanfaatkan secara maksimal. Selama ini aspal Buton dimanfaatkan sebagai material pelapis permukaan jalan, pengganti aspal minyak, blok asbuton, genteng asbuton, diekstraksi bitumennya, pelapis bendung/embung dan kontruksi.

Menurut [1] mengemukakan tantangan masa depan bagi industri pengilangan minyak mentah harus mampu mengatasi umpan berat dengan kualitas rendah. Benito dan Martínez [1] melakukan perengkahan katalitik terhadap residu aspal syncrude yang diperoleh pada pelelehan batubara subbitumen dari Spanish. Rankel [2] menggunakan Ni-W yang diembankan pada alumina, silika alumina, US-Y, montmorilonit, sepiolit dan karbon aktif untuk proses hidrorengkah dengan umpan residu vakum fraksi berat dari Arab. Proses impregnasi kemudian dilakukan kalsinasi, oksidasi dan reduksi.

Umpan Aspalten. Umpan aspal dibuat dari aspal mentah Buton yang diambil dari Kabungka, Buton. Pembuatan umpan ini dilakukan dengan cara ekstraksi sokhlet. Ektraksi ini dilakukan dalam dua tahap yaitu: tahap pertama diektraksi dengan $\mathrm{n}$ - pentana kemudian tahap kedua diekstraksi dengan benzena.

Nomura, dkk. [3] melakukan hidrorengkah katalitik dengan umpan fraksi aspalten tidak larut pentana (pentane-insoluble), berasal dari fraksi berat residu vakum campuran minyak mentah Arab dari Nippon Oil 
Ltd. Co. menggunakan katalis Pd-Ni yang diembankan pada zeolit type Y.

Berdasarkan penelitian-penelitian tersebut di atas belum pernah dilakukan penelitian dengan menggunakan bahan dasar aspalten dari Buton dan katalis Mo- Ni $/ \gamma$-alumina. Pada penelitian ini akan ditentukan pengaruh temperatur terhadap produk hidrorengkah fraksi aspalten pentana insolublebensena soluble dari aspal Buton dengan temperatur antara $250^{\circ} \mathrm{C}$ sampai $400^{\circ} \mathrm{C}$ dengan rentang kenaikan temperatur $50^{\circ} \mathrm{C}$ menggunakan katalis $\mathrm{Mo}-\mathrm{Ni} / \gamma^{-}$ alumina untuk menentukan konversi produk

\section{Metodologi}

Katalis Mo-Ni $/ \gamma$-alumina. Katalis dibuat dengan mengimpregnasikan garam $\mathrm{Ni}\left(\mathrm{NO}_{3}\right)_{2} \cdot 6 \mathrm{H}_{2} \mathrm{O}$ sebagai sumber logam nikel dan $\left(\mathrm{NH}_{4}\right)_{6} \mathrm{Mo}_{7} \mathrm{O}_{24} \cdot 4 \mathrm{H}_{2} \mathrm{O}$ sebagai sumber logam molibden dengan pengemban $\gamma$-alumina. Perbandingan antara logam total dan pengemban adalah 1:10, sedang perbandingan antara Ni dan Mo adalah 4:1. Setelah hasil ekstraksi tahap kedua diambil dan dievaporasi kemudian ditimbang sampai beratnya tetap, dan disebut fraksi pentane insoluble-benzena soluble (tak larut pentana-larut benzena atau PI-BS) yang digunakan sebagai umpan hidrorengkah.

\section{Hidrorengkah fraksi PI-BS.}

Perengkahan fraksi PI-BS dilakukan dengan reaktor Autoclave system batch di Laboratorium Teknologi Minyak Bumi, UGM , buatan Autoclave Enginering, Ltd, dengan dimensi bagian dalam diameter $7 \mathrm{~cm}$ dan tinggi $20 \mathrm{~cm}$ dengan tempat sampel diameter $5 \mathrm{~cm}$ dan tinggi $10 \mathrm{~cm}$. Katalis: umpan ditimbang masing-masing 0,5 g: $1 \mathrm{~g}$ (rasio katalis: umpan = 1:2) kemudian ditempatkan dalam wadah sebagai tempat reaksi dan dimasukkan ke dalam reaktor. Reaktor kemudian ditutup rapat dan diisi gas hidrogen dengan tekanan 10 atm. Selanjutnya reaktor diaktifkan dengan pemanasan untuk menaikkan temperatur secara perlahan sampai pada temperatur yang dikehendaki, setelah temperatur reaksi tercapai dijaga agar konstan selama 1 jam (waktu tinggal 1 jam). Temperatur hidrorengkah dalam penelitian ini adalah 250, 300, 350 dan $400^{\circ} \mathrm{C}$

Hasil hidrorengkah yang berupa cairan dan padatan diambil dengan tetrahidrofuran (THF) dan disaring dengan kertas saring wathman 42 untuk dipisahkan dari katalis dan kokasnya. Konversi diperhitungkan dari sisa katalis dan kokas sehingga \% konversi dinyatakan:

$$
\% \text { konversi }=\frac{W_{\text {umpan }}-W_{\text {kokas }}}{W_{\text {umpan }}} \times 100 \%
$$

di mana

$\mathrm{W}_{\text {umpan }}=$ berat umpan mula-mula

$\mathrm{Wk}_{\mathrm{o}} \mathrm{ka}_{\mathrm{s}}=$ berat kokas (berat yang tidak lolos kertas saring dikurangi katalis)

\section{Hasil dan Pembahasan}

Proses perengkahan aspal Buton fraksi PI-BS pada penelitian ini menggunakan proses hidrorengkah, dengan tujuan untuk memperoleh konversi tertinggi pada rentang temperatur $250-400{ }^{\circ} \mathrm{C}$ dengan keanikan temperatur $50^{\circ} \mathrm{C}$, rentang ini dipilih karena di bawah temperatur kalsinasi, oksidasi dan reduksi katalis. Hal tesrbut diharpkan katalis dapat bekerja secara optimal dan tidak rusak atau berubah struktur selama digunakan untuk proses hidrorengkah. Tekanan awal yang diberikan ke dalam reaktor adalah sebesar 10 atm, sedangkan tekanan operasi akan naik sesuai dengan temperatur yang dipakai yang berkisar antara $17-24$ atm. Waktu tinggal dalam reator batch ditetapkan selama 60 menit per temperatur, sehingga diharapkan diperoleh data yang cukup akurat untuk menentukan persamaan hubungan antara konversi dan temperatur.

Hasil konversi hidrorengkah dihitung sebagai (100kokas)\% disajikan pada grafik sebagai berikut:

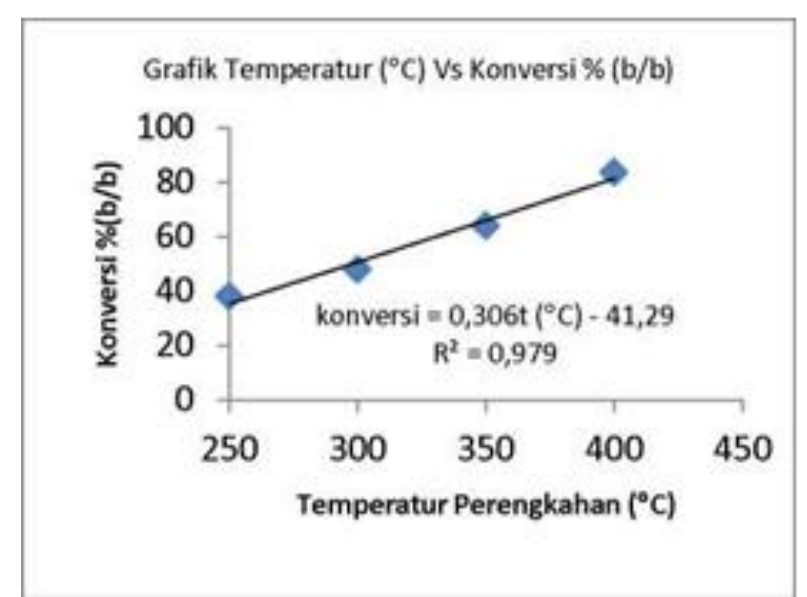

Gambar 1. Grafik temperatur perengkahan $\left({ }^{\circ} \mathrm{C}\right)$ vs konversi \%(b/b)

Hasil hidrorengkah fraksi PI-BS menunjukkan kenaikan konversi yang cukup tinggi, sesuai dengan kenaikan temperatur. Kenaikan temperatur bagi fraksi aspal mengakibatkan semakin banyak fraksi aspal yang meleleh menjadi cair bahkan mungkin sebagian menjadi fraksi gas, sehingga vibrasi molekul menjadi lebih tinggi. Tingginya kekuatan vibrasi molekular yang melebih ambang batas bisa menyebabkan terputusnya ikatan antar atorm, sehingga kemudian terbenlah fraksi-fraksi molekul yang lebih pendek. Adanya katalis membantu proses pemecahan fraksi aspal menjadi molekul- molekul lebih pendek dengan proses kemisorpsi. Pada temperatur $400^{\circ} \mathrm{C}$ diperoleh konversi dari padatan aspal menjadi fraksi cari dan gas paling besar. Hal ini sebabkan efektifitas pemutusan molekul aspal baik oleh temperatur maupun katalis yang ditambahkan semakin efektif. Sedangkan pada temperatur yang lebih rendah proses perubahan fasa dan juga vibrasi molekul farksi aspal ini tidak sekuat pada temperatur $400^{\circ} \mathrm{C}$, demikian juga dengan efektifitas katalis pada temperatur dibawah $400^{\circ} \mathrm{C}$ menjadi kurang effektif dalam mengadsorbsi reaktan yang disebabkan oleh cairan atau padatan yang masih 
melingkupi katalis tersebut, sebagai akibatnya maka konversi yang diperoleh menjadi lebih rendah dan terendah diperoleh pada temperatur $250^{\circ} \mathrm{C}$.

Hasil konversi hidrorengkah pada penelitian ini diperoleh kenaikan konversi yang mengikuti persamaan linear: konversi $\%(b / b)=0,306 \mathrm{t}\left({ }^{\circ} \mathrm{C}\right)-41,29$ dengan $\mathrm{R}$ $=0,979$. Persamaan yang diperoleh dapat digunakan untuk memperkirakan konversi yang diperoleh pada tiap temperatur perengkahan dengan kondisi yang sama.

\section{Kesimpulan}

Dari hasil penelitian dan pembahasan terhadap proses hidrorengkah fraksi tak larut pentana-larut benzena (PI- BS) dari aspal Buton dengan katalis Mo$\mathrm{Ni} / \gamma$-alumina diperoleh kesimpulan bahwa hasil konversi meningkat secara linear mengikuti persamaan persamaan berikut: konversi $\%(\mathrm{~b} / \mathrm{b})=0,306 \mathrm{t}\left({ }^{\circ} \mathrm{C}\right)-$ 41,29 .

\section{Daftar Pustaka}

[1] A. M. Benito, M. T. Martínez, Catalytic Hydrocracking of an Asphaltenic Coal Residue, Energy \& Fuels, 10 (1996) 1235-1240.

[2] Lillian A. Rankel, Hydrocracking vacuum resid with Ni-W bifunctional slurry catalysts, Fuel Processing Technology, 37 (1994) 185-202.

[3] Masakatsu Nomura, K Kidane, S Murata, Y Su, L Artok, Y Miyatani, Structure and reactivity of the asphaltene fraction of an Arabian light-medium crude mixture, in: Proceedings of the 218th ACS National Meeting, 1999, pp. 22-26. 